\title{
Electric Drilling versus Cold Steel Instruments in Correction of a Spur of the Maxillary Crest of the Nasal Septum
}

\author{
Original \\ Article \\ Tarek Abd-Elrahman Abd-Elhafez, and Ahmad Mahmoud Hamdan \\ Department of Otorhinolaryngology, Faculty of Medicine, Menoufia University, Egypt.
}

\begin{abstract}
Objective: To compare electric drilling versus cold steel instruments in management of spur of maxillary crest of the nasal septum regarding operative details and postoperative complications.

Patients and Methods: This was a prospective comparative study evaluating two techniques for management of spur of maxillary crest of the nasal septum. Patients of the study were divided into two groups 32 patients each. In group I, the spur of the maxillary crest was removed using surgical instruments. In group II, the spur was removed using electric drilling. The two groups were compared regarding duration of maxillary crest spur removal, the amount of blood loss, the incidence of unilateral and bilateral flap injury, the incidence of anesthesia of the upper incisors and the incidence of septal perforations.

Results: In the current study, operative blood loss was less in group II with a highly significant difference $(p=0.0002)$. However, operative duration was less in group I with a highly significant difference $(p<0.0001)$. There was a nonsignificant difference between the two groups regarding flap injury with higher incidence in group I $(p=0.6)$. The incidence of upper incisors anesthesia was significantly more in group I $(p=0.03)$. There was a non-significant difference regarding the incidence of septal perforation $(p=1)$.

Conclusion: Both techniques are effective for correction of spurs of the maxillary crest with significantly better control of intraoperative bleeding and less postoperative central incisors anesthesia with electric drilling. However, the drilling technique consumed significantly more time.
\end{abstract}

Key Words: Cold steel instruments, drilling, maxillary crest, septal deviation, spur.

Received: 30 July 2020, Accepted: 31 August 2020

Corresponding Author: Ahmad Mahmoud Hamdan, MD, Department of Otorhinolaryngology, Faculty of Medicine, Menoufia University, Shebin El-Kom, Egypt, Tel.: 00201008993175, E-mail: Ahmed.Hamdan@med.menofia.edu.eg

ISSN: 2090-0740, 2021 Vol.22

\section{INTRODUCTION}

The lowest part of the septum is a narrow strip of bone that projects from the maxilla and the palatine bones along the length of the septum and is called the maxillary crest. This crest, with its maxillary and palatine components, articulates anteriorly with the quadrangular cartilage, and posteriorly with the vomer bone. ${ }^{[1]}$

Nasal septal deviation constitutes one of the most prevalent causes of nasal obstruction among the population. ${ }^{[2]}$ Different morphologies of deviated septum exist including spur of the maxillary crest which represents one of the surgical challenges for surgical correction. ${ }^{[3]}$ Maxillary crest and septal floor deviations can impair overall flow patterns. Physiologic airflow models have shown that $50 \%$ of inspired air passes along the nasal floor. Surgical corrosion of these problems improves overall flow and decreases the obstructive sensation. Hence, the importance of correction of spur of the maxillary crest once present in cases indicated for septal surgery for persistent nasal obstruction. ${ }^{[4]}$
Surgical correction of a spur of the maxillary crest carries a risk of injury to one or both mucoperichondrial flaps with a risk of development of nasal septal perforation. Surgical instruments including hammer and gouge have been routinely used to remove such spurs. ${ }^{[5]}$ The aim of this study was to compare electric drilling versus cold steel instruments in management of spur of maxillary crest of the nasal septum regarding operative details and postoperative complications.

\section{PATIENTS AND METHODS:}

The current study was a prospective comparative study evaluating two techniques for management of spur of maxillary crest of the nasal septum. Approval of the institutional review board of the faculty was taken and a written consent was taken from every patient before participation in the study.

Adult patients with a spur of the maxillary crest of the nasal septum as detected clinically and confirmed by computed tomography of the nose and paranasal sinuses 
were included in the study. Any patient with previous septal surgery or surgical unfitness (uncontrolled systemic diseases or bleeding tendency) was excluded from the study.

Patients of the study were divided into two groups each including 32 patients according to sample size estimation. In group I patients, the spur of the maxillary crest was removed using surgical instruments, namely, hammer and fishtail gouge. In group II patients, the spur was removed using electric drilling.

Patients of the study were evaluated preoperatively with history taking to detect the presence of persistent nasal obstruction not responding to medical treatment. Endoscopic assessment of the nasal septum and computed tomography of the nose and paranasal sinuses, coronal and axial cuts were done to detect the presence of spur of the maxillary crest of the nasal septum. Routine preoperative laboratory investigations were performed for the patients (including complete blood picture, coagulation profile, liver and kidney function tests.

All patients were operated under general anesthesia along with local surface and infiltration anesthesia using submucos resection technique to provide accessibility to the maxillary crest. The classic "two tunnel" technique was used to approach prominent spurs of the maxillary crest. A superior "tunnel" was elevated over the cartilaginous septum above the spur, and a second tunnel was elevated below the spur, along the nasal floor and the inferior aspect of the maxillary crest. The dissection was then joined at the apex of the spur, with great care being taken to avoid tearing the thin mucosa overlying the apex of the spur.

In group I patients, the spur of the maxillary crest was removed using cold steel surgical instruments, namely, hummer and fishtail gouge. In group II patients, the spur was removed using an electric drilling at a speed of 40,000 RPM using $12 \mathrm{~cm}$ length burrs with a $4.5 \mathrm{~mm}$ diameter cutting and diamond heads with the flaps being protected by the blades of a Killian speculum along with continuous saline washing to minimize the associated heat. The duration of maxillary crest spur removal and amount of blood loss calculated by subtraction of the amount of saline wash from the suctioned fluid from the operative field were assessed and documented.

\section{Outcomes:}

The outcomes of the study included comparison between the two groups regarding the operative details including the duration of maxillary crest spur removal in minutes, the amount of blood loss and the incidence of unilateral and bilateral mucoperichondrial flap injury. Also, the outcomes of the study included comparison between the two groups regarding postoperative complications including the incidence of anesthesia of the upper incisors and the incidence of septal perforations.

\section{Statistical Analysis}

Data were collected, tabulated and statistically analyzed using Statistical Package of Social Science (SPSS) version 23, (IBM Corp, Armonk, NY, USA). Descriptive statistics for quantitative data were presented as mean $(\mathrm{X})$ and standard deviation (SD). Qualitative data were presented as numbers and percentages (\%). Data turned up to be nonnormally distributed according to Kolmogorov-Smirnov test. Chi square test and Fischer Exact teats were used to compare qualitative data of both groups. Mann Whitney U test was used to compare quantitative data of both groups. Two-sided $\mathrm{p}$ value of $(<0.05)$ was considered statistically significant, while $p<0.001$ was considered highly significant.

\section{RESULTS:}

In the current study, the mean age of both study groups was 30.78 and 32.75 respectively with a non-significant difference between the two groups $(p=0.25)$. Group I included 20 males $(62.5 \%)$ while group II included 24 males $(75 \%)$ with a non-significant difference between the two groups $(p=0.28)$ (Table 1).

In the current study, operative blood loss was less in group II compared with group I with a highly significant difference $(p=0.0002)$. However, operative duration was less in group I compared with group II with a highly significant difference $(p<0.0001)$. There was a nonsignificant difference between the two group regarding intraoperative flap injury with group I having a higher incidence of flap injury compared with group II $(p=0.6)$ (Table 2).

In the current study, the incidence of upper incisors anesthesia was more in group I compared with group II with a significant difference $(p=0.03)$ However, there was a non-significant difference between the two groups regarding the incidence of septal perforation $(p=1)$ (Table 3). 
Table 1: Comparison between study groups regarding demographic

\begin{tabular}{|c|c|c|c|c|c|c|c|}
\hline \multicolumn{2}{|c|}{ Item } & \multicolumn{2}{|c|}{ Group I } & \multicolumn{2}{|c|}{ Group II } & Statistical test & $P$ value \\
\hline \multirow{2}{*}{\multicolumn{2}{|c|}{ Age Mean \pm SD }} & \multicolumn{2}{|c|}{$30.78 \pm 7.17$} & \multicolumn{2}{|c|}{$32.75 \pm 6.57$} & $\mathrm{z}=-1.15474$ & 0.25 \\
\hline & & No & $\%$ & No & $\%$ & & \\
\hline \multirow[t]{2}{*}{ Sex } & Male & 20 & 62.5 & 24 & 75 & Chi=1.1636. & 0.28 \\
\hline & Female & 12 & 37.5 & 8 & 25 & & \\
\hline
\end{tabular}

Table 2: Comparison between study groups regarding operative details:

\begin{tabular}{|c|c|c|c|c|c|c|c|}
\hline \multicolumn{2}{|l|}{ Item } & \multicolumn{2}{|c|}{ Group I (Instrument) (32) } & \multicolumn{2}{|c|}{ Group II (Drill) (32) } & Statistical test & Pvalue \\
\hline \multicolumn{2}{|c|}{ Operative bleeding $($ Mean \pm SD) } & \multicolumn{2}{|c|}{$125.31 \pm 7.61$} & \multicolumn{2}{|c|}{$115 \pm 10.78$} & $z=-3.68575$ & 0.0002 \\
\hline \multirow{2}{*}{\multicolumn{2}{|c|}{ Operative duration $($ Mean \pm SD) }} & \multicolumn{2}{|c|}{$8.53 \pm 0.97$} & \multicolumn{2}{|c|}{$10.97 \pm 1.33$} & $z=-5.80724$ & $<0.00001$ \\
\hline & & No & $\%$ & No & $\%$ & & \\
\hline \multirow[t]{3}{*}{ Flap injury } & Unilateral & 11 & 34.4 & 8 & 25 & $\mathrm{Chi}=1.0292$ & 0.6 \\
\hline & Bilateral & 5 & 15.6 & 4 & 12.5 & & \\
\hline & No & 16 & 50 & 20 & 62.5 & & \\
\hline
\end{tabular}

z: $\mathrm{z}$ value of Mann Whitney U test

Table 3: Comparison between study groups regarding postoperative details:

\begin{tabular}{|c|c|c|c|c|c|c|c|}
\hline \multicolumn{2}{|c|}{ Postoperative complication } & \multicolumn{2}{|c|}{ Group I (32) } & \multicolumn{2}{|c|}{ Group II (32) } & \multirow[t]{2}{*}{ Statistical test } & \multirow[t]{2}{*}{$P$ value } \\
\hline & & No. & $\%$ & No. & $\%$ & & \\
\hline \multirow{2}{*}{$\begin{array}{l}\text { Upper incisors } \\
\text { numbness }\end{array}$} & Yes & 13 & 40.6 & 4 & 12.5 & \multirow[t]{2}{*}{$\mathrm{Chi}=4.9469$} & \multirow[t]{2}{*}{0.03} \\
\hline & No & 19 & 59.4 & 28 & 87.5 & & \\
\hline \multirow{2}{*}{$\begin{array}{l}\text { Septal } \\
\text { perforation }\end{array}$} & Yes & 4 & 12.5 & 3 & 9.4 & \multirow{2}{*}{\multicolumn{2}{|c|}{ Fischer Exact test $\mathrm{P}=1$}} \\
\hline & No & 28 & 87.5 & 29 & 90.6 & & \\
\hline
\end{tabular}

\section{DISCUSSION}

One of the more frequently observed septal deviations occurs when the quadrilateral cartilage has shifted laterally off the crest or there is a deviation of the crest itself resulting in nasal floor obstruction. The etiology for such pathology can be attributed to early trauma with crest fracture or cartilage growth with a shallow groove of the maxillary crest ${ }^{[6]}$. Trauma in early childhood is an important factor because the maxillary crests and vomer are not completely ossified, and a slight shifting of these tissues may cause the crest and vomer, as they develop, to grow to the side. This situation results in a flattening of the vomerian groove and the loss of its lip on the side of deviation. Some of these deviations may have their origin in birth trauma. ${ }^{[4]}$

The classic technique for correction of maxillary crest spur requires bilateral mucoperichondrial flap elevation with extension of the elevation along the nasal floor. A Cottle elevator or a No. 15 blade can then be used to excise the deviated cartilaginous part, and a 4-mm osteotome is usually used for any bony deviation. ${ }^{[7]}$ The aim of this study was to compare the use of surgical instruments and electric drilling in correction of spur of the maxillary sinus trying to find an alternative technique with less blood loss and postoperative complications.

Removal of maxillary crest spur is usually associated with troubling bleeding. This is due to the variably located incisive artery and its associated neural fibers which are found at the superior border of the vomer. This neurovascular bundle may be injured when trimming a badly deviated maxillary crest or when elevating the periosteum. Control of bleeding from this site may be obtained by infiltrating the incisive foramen from below, "plugging" the site from above, or carefully using suction Bovie cautery ${ }^{[6]}$. In the current study, the average blood loss in the two groups was 125.31 and $115 \mathrm{~mL}$ respectively with a highly significant difference. The lower blood loss with electric drilling can be explained by the crushing effect of drilling while removing the crest minimizing the blood loss compared with the use of hammer and gouge.

In the current study, the average operative duration was less in group I (8.53 minutes) compared with group II (10.97 minutes) with a highly significant difference $(p<0.0001)$. This can be explained by the 
powerful effect of surgical instruments on bone cutting compared with the relatively slow action of the drill on the bone with need to address multiple points of the spur with the drilling burr. However, from practical point of view, the nearly 2.5 minute difference between the two groups can be considered insignificant by some surgeons.

In the current study, there was a non-significant difference between the two groups regarding the incidence of flap injury with a higher incidence of unilateral flap injury in the two groups (34.4\% and $25 \%$ respectively) than bilateral flap injury $(15.6 \%$ and $12.5 \%$ respectively). The transition from mucoperichondrium to mucoperiosteum at the maxillary crest leads to difficult dissection, and thus tearing the mucoperichondrium may be unavoidable. ${ }^{[6]}$ The septal flap is often tethered inferiorly at the transition between the quadrangular cartilage and bony maxillary crest by decussating fibers that divide the perichondrium of the cartilage from the periosteum of the bone. To minimize flap injury at the spur, sharp dissection of these fibers with sharp dissector or sharp tip scissors should be done to facilitate a smooth transition of the flap at this point. Once a unilateral flap has been elevated, it should be protected with a nasal speculum. When encountering a septal spur, it is necessary to tunnel above and under the spur with a Cottle elevator and eventually join the two tunnels at the apex of the spur ${ }^{[8]}$. Any septal flap injury should be repaired with 5-0 vicryl sutures, and, if bilateral flap tears are present, not only should they be repaired, but also an interposition graft of crushed cartilage should be placed. This interposition graft significantly decreases the chance of permanent perforation. ${ }^{[6]}$

After resection or trimming of the maxillary crest or work on the nasal spine, patients may complain of numbness or pain of the central incisors or of the mucosa of the hard palate just posterior to the incisors. This lack of sensation or complaint of pain is generally a short-lived phenomenon. This symptoms arises from lesions of the nasopalatine nerve near the floor of the nose. ${ }^{[6]}$ Chandra et al. ${ }^{[9]}$ assessed anterior palate sensory impairment after 107 septal surgery. The general incidence of anterior palatal numbness was $2.8 \%(3 / 107)$. In this study, out of the eleven cases with spur of the maxillary crest which was removed by a chisel 3 patients (27.2 reported postoperative numbness. Almansoori ${ }^{[10]}$ reported that only one out of 48 cases with spur of the maxillary crest managed by electric drilling $(2.1 \%)$ reported anesthesia of the upper incisors. In the current study, the reported incidence of central incisors numbness in the two groups were $40.6 \%$ and $12.5 \%$ respectively. The lower incidence with electric drilling can be attributed to the less mechanical trauma associated with electric drilling. However, the associated heat of drilling was neutralized by frequent intraoperative saline wash.

Dąbrowska-Bień et $a l^{[11]}$ in their study based on a large group of 5639 patients, the incidence of septal perforation was $2.3 \%$. In the current study, the incidence of septal perforation in the two groups were $12.5 \%$ and $9.4 \%$ respectively with a non-significant difference $(p=1)$. The higher incidence of septal perforation in our study can be explained by the restriction of our study to cases with spur of the maxillary crest which required more manipulations and dissection with higher incidence of flap injury.

\section{CONCLUSION}

Both cold steel surgical instruments and electric drilling are effective for correction of spurs of the maxillary crest with significantly better control of intraoperative bleeding and less postoperative central incisors anesthesia with electric drilling. However, the drilling technique consumed significantly more time. No significant difference existed between the two techniques regarding incidence of flap injury or septal perforation.

\section{CONFLICT OF INTEREST}

There are no conflicts of interest.

\section{REFERENCES}

1. Godley FA. Nasal Septal Anatomy and Its Importance in Septal Reconstruction. Ear Nose Throat J. 1997; 76(8):498-501, 504-6.

2. Mladina R, Cujić E, Subarić M, Vuković K. Nasal septal deformities in ear, nose, and throat patients: an international study. Am J Otolaryngol. 2008 Mar-Apr; 29(2):75-82.

3. Teixeira J, CertalV, Chang ET, Camacho M.Nasal Septal Deviations: A Systematic Review of Classification Systems. Plast Surg Int. 2016;2016:7089123.

4. Tardy ME Jr. Nasal Reconstruction and Rhinoplasty. In: Snow JB Jr, Ballenger JJ, eds. Ballenger's Otorhinolaryngology Head and Neck Surgery. Sixteenth Edition. Ontario, BC Decker Inc, 2003: 842972

5. Most SP, Rudy SF. Septoplasty: Basic and Advanced Techniques. Facial Plast Surg Clin North Am. 2017 May;25(2):161-169. 
6. Kridel RW, Kelly PE, Holzapfel AM. The Nasal Septum. In: Flint PW, Haughey $\mathrm{BH}$, Lund VJ, et al, eds. Cummings Otolaryngology Head \& Neck Surgery. Fifth edition. Philadelphia, Mosby Inc, 2010, 481-495.

7. Fettman N, Sanford T, Sindwani R. Surgical management of the deviated septum: techniques in septoplasty. Otolaryngol Clin North Am. 2009; 42(2):241-viii.

8. Kanowitz SJ. Deviated Nasal Septum. In: Kountakis SE, ed. Encyclopedia of Otolaryngology, Head and Neck Surgery. Berlin Heidelberg. Springer-Verlag. 2013: 688-693
9. Chandra RK, Rohman GT, Walsh WE. Anterior palate sensory impairment after septal surgery. Am J Rhinol. 2008;22(1):86-88.

10. Almansoori SH. Bone spur drilling, a new technique to correct deviated maxillary crest. Bas J Surg, June. 2018; 24: 15-19.

11. Dąbrowska-Bień J, Skarżyński PH, Gwizdalska I, Łazęcka K, Skarżyński H. Complications in septoplasty based on a large group of 5639 patients. Eur Arch Otorhinolaryngol. 2018;275(7):1789-1794. 